\title{
Pain management in urology training: A national survey of senior residents
}

\author{
Jonathan Pace, MD; Melanie Jaeger, MD; ${ }^{+}$J. Curtis Nickel, MD, FRCSC; ${ }^{*}$ D. Robert Siemens, MD, FRCSC*
}

`Department of Urology, Queen's University, Kingston, ON; 'Department of Anesthesiology and Perioperative Medicine, Queen's University, Kingston, ON

See related article on page 462.

Cite as: Can Urol Assoc J 2013;7(11-12):456-61. http://dx.doi.org/10.5489/cuaj.1562 Published online December 5, 2013.

\section{Abstract}

Introduction: We explore the attitudes and experience of urology residents toward acute and chronic pain management during their training.

Method: A convenience sample of Canadian Urology chief residents were invited to complete an anonymous questionnaire involving both open and closed-ended questions using a 5-point Likert scale. Descriptive and quantitative statistics were used to analyze the attitudes toward pain management, including their experience and training issues.

Results: The response rate was $97 \%$. Most residents agreed or strongly agreed that more formal training in acute pain $(77 \%$ agreement, mean $4.03 \pm 0.98 \mathrm{SD})$ and chronic pain $(68 \%, 3.97 \pm 0.95)$ management would be valuable in urology residency with only 1 respondent disagreeing that training should be mandatory. There was a significant difference of training experience in chronic versus acute pain management, with only $13 \%$ agreement $(2.99 \pm 0.67)$ that their training in chronic pain was adequate. Most residents agreed $(74 \%, 3.84 \pm 1.00)$ that most of their training in pain management came from their senior residents or fellows. Many of the residents $(65 \%, 3.61 \pm 0.84)$ felt that they could manage their patients' acute pain issues independently, even in the absence of an acute pain service, although apparent knowledge of opioids was poor.

Conclusions: The results of this survey suggest that urology residents attain their knowledge of pain management experientially with what may be insufficient formal training, particularly in chronic pain. These observations are limited by the relatively small number of respondents and by the nature of a cross-sectional, self-reported survey; however, they would appear to underscore a need to redouble efforts in residency education.

\section{Introduction}

Urologists see patients in pain daily and must manage acute and chronic pain-related issues in hospital and ambulatory settings. ${ }^{1}$ Beyond the common issues presenting to the average urologist in the acute surgical setting, up to $6 \%$ of outpatient visits will involve pain management in patients with chronic prostatitis/chronic pelvic pain syndrome, interstitial cystitis/bladder pain syndrome, chronic epididymitis and orchiodynia. ${ }^{2}$ In addition, a urologist's oncologic practice may include chronic cancer-related pain involving multifaceted management strategies. As patients' medical issues become increasingly complex, an in-depth understanding of the options available in pain management by the urologist is required in today's practice. ${ }^{3}$

A recent survey of medical oncologists in the United States revealed that although they agreed their discipline required expertise in pain management, they felt that their training in this area was fair. ${ }^{4}$ Furthermore, a high prevalence of deficits in the knowledge of opioids was evident in this group of specialists. In a similar study, surgeons had the lowest scores in knowledge of cancer-related chronic pain management. ${ }^{5}$ There is little known regarding the quality of training in pain management for residents in surgery programs in general or urology specifically. The goal of this study was to gain a deeper understanding of the type and quality of education we are providing to residents in urology, by exploring their attitudes and experiences in acute and chronic pain management during their training.

\section{Methods}

This prospective study surveyed a sample of postgraduate year-5 (PGY-5) residents in Canadian urology training programs $(n=32)$ at a review course held in 2012, representing most chief residents in urology at the time. Participation was completely voluntary and confidentiality was maintained at 
all times, as no identifying information was recorded in the survey results. Ethics approval was attained from the Queen's University institutional review board and explanations for the objectives of the study and assurance of confidentiality were distributed to the residents responding to the survey.

The questionnaire consisted of closed-ended questions using a 5-point Likert scale designed to explore the experience, attitudes and knowledge regarding pain management in urology training programs. Open-ended questions were also utilized to explore resources and barriers to knowledge acquisition, as well as to gauge respondents' level of understanding of medications commonly utilized in acute and chronic pain management.

Initial questions on the survey assessed demographic information, background and career aspirations, as well as past experience with teaching and evaluation of pain management in medical school and in residency. The rest of the questions addressed the above-described objectives, including attitudes and experiences regarding formal training and resident participation in acute and chronic pain management. The survey explicitly attempted to differentiate attitudes and experience in acute pain compared to chronic pain, either cancer or non-cancer related. Questionnaire development resulted from an initial experience with a previous survey construction for similar attitudes for specialty residents. ${ }^{6}$ Residents and educators involved in both undergraduate and postgraduate programs were asked to assess and modify the survey for clarity.

Descriptive statistics were used to describe the demographics and background information of respondents. Responses to the questions using the 5-point Likert scale are described as means \pm standard deviation. For ease of reporting, agreement responses of 4 and 5 were grouped, as were the disagreement responses of 1 and 2 . All other quantitative statistics used the full 5-point Likert scale. A Mann-Whitney test was used to compare Likert scale scores between respondents between the 2 years of the study and between specifically linked questions. Spearman or Pearson tests, depending on normality of distribution, were used to demonstrate correlations of respondents to questions using the Likert scale. The GraphPad Prism 4 statistical software package (GraphPad Software, Inc., San Diego, CA) was used for analysis.

\section{Results}

There was a $97 \%$ response rate from all the chief residents in this convenience sample (31/32). In total, 81\% (mean Likert score $4.58 \pm 1.31 \mathrm{SD}$ ) of the respondents agreed that they were likely to undertake further fellowship training upon graduation from their urology program. The residents were evenly split with respect to their preferred practice type after training; $35 \%$ said they would prefer a community practice and $40 \%$ agreed or strongly agreed they would prefer an academic practice. Oncology and minimally invasive surgery were the most likely fellowships to be completed by the respondents (55\%). Residents were asked about the pain management environment and where they completed most of their training. Most (97\%) agreed that both acute pain management services (APMS) and palliative care services were present in the hospitals where they did most of their training. Similarly, $90 \%$ said there was a chronic pain clinic at the institution where they completed their core training. Interestingly, 42\% of the residents responded that they had completed rotations in hospitals where there was no APMS present. There was no association between those who had completed rotations in hospitals without APMS and their responses regarding the adequacy of pain management training.

In regards to educational experiences in pain management, only $23 \%$ (mean Likert score $2.93 \pm 0.81$ ) of residents agreed that they had received a strong undergraduate medical curriculum in pain management. Similarly, only $26 \%(2.87 \pm 1.12)$ and $19 \%(2.54 \pm 0.09)$ agreed that they had received formal training in acute and chronic pain management, respectively, within their residency program. On the contrary, $48 \%$ disagreed or strongly disagreed that they had received any formal education focused on chronic pain during their specialty training (correlation coefficient $0.492, p=0.005)$. Only 4 residents responded that they had completed an elective or selective in which pain management was a significant part of the rotation objectives (i.e., Anesthesiology, Oncology/Palliative Care) and this was not associated with responses regarding adequacy of training. Although the respondents were consistent in their recommendation that more formal training in acute and chronic pain (correlation coefficient $0.749, p<0.001$ ) would be valuable (Fig. 1), they were ambivalent in their responses regarding whether or not it should be mandatory; only $52 \%$ agreed $(3.61 \pm 0.844)$.

Despite the apparent lack of any formal training, 74\% (3.64 \pm 0.75$)$ still felt that their training was adequate in acute pain management, compared to only $13 \%(2.77 \pm 0.67)$ agreeing that their training was adequate in chronic pain management $(p<0.001)$. Indeed, 65\% (mean $3.61 \pm 0.844)$ of the residents agreed that their patients' acute pain was well-managed even without an APMS, whereas only 3 disagreed with this statement. This discrepancy could be a result of "learning on the fly" and indeed most residents, $74 \%(3.84 \pm 1.00)$, agreed that they had received most of their acute pain training from their peers, presumably in clinical settings in the hospital. On the contrary, only $16 \%$ $(2.77 \pm 0.845)$ agreed they had had a strong role model on which to base their chronic pain understanding (Fig. 1). When asked to rank the resources that were most influential in their pain management training, residents seem to confirm that most of their training is experiential, ranking their fellow 
Pace et al.

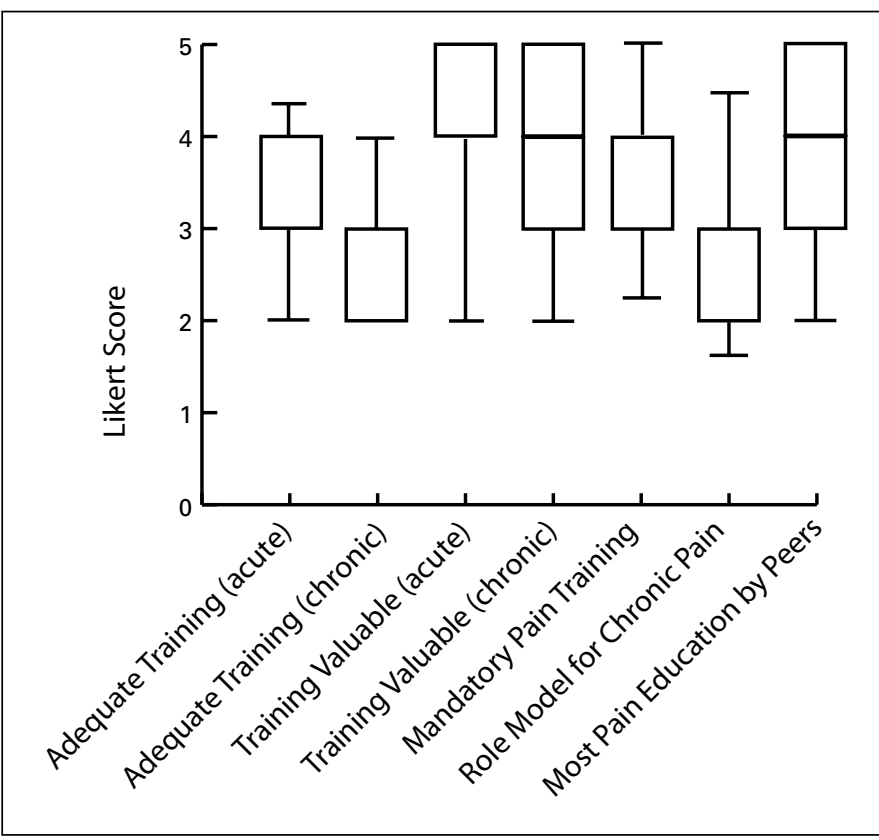

Fig. 1. Pain management training in urological training programs. Box and whisker plot (mean, 95\% confidence limit) of Likert score responses to survey questions on attitudes towards training in pain management during residency training.

residents, nurses and physicians on the APMS as the most influential (Fig. 2).

When asked about their experiences of and barriers to the management of urological patients with chronic pain, all but 2 respondents knew how to contact a chronic pain clinic, but $55 \%$ (3.85 \pm SD 1.29) agreed it was difficult or very difficult to get an appointment for their patients. Residents did not feel $(71 \%)$ that pain specialists were reluctant to see patients with cancer-related chronic pain, but only a third of them $(32 \%)$ agreed with respect to patients with non-cancer related chronic pain, such as orchalgia $(p=0.002)$. Most residents responded that they felt that their patients' self-reported pain severity was generally accurate for those with both acute $(3.742 \pm 0.893)$ and chronic pain $(3.581 \pm 0.991)$.

Seventy-seven percent of respondents agreed that opioids are most-often used for non-cancer chronic pain in urological conditions. Only 1 resident was aware of guidelines for the management of chronic cancer pain and no one agreed that they were aware of any opioid prescribing guidelines in their regions $(1.935 \pm 0.574)$. Fig. 3 summarizes potential barriers to managing patients with chronic pain within a urological practice. Based on their experiences in training, most perceived that there is a lack of physician understanding of chronic pain management and over $77 \%$ agreed that meeting patient expectations with chronic pain is difficult. There was a significant difference in responses on perceived difficulties in patient/physician relationships between those with cancer-related and non-cancer related chromic pain $(p<0.001$, one-way ANOVA).

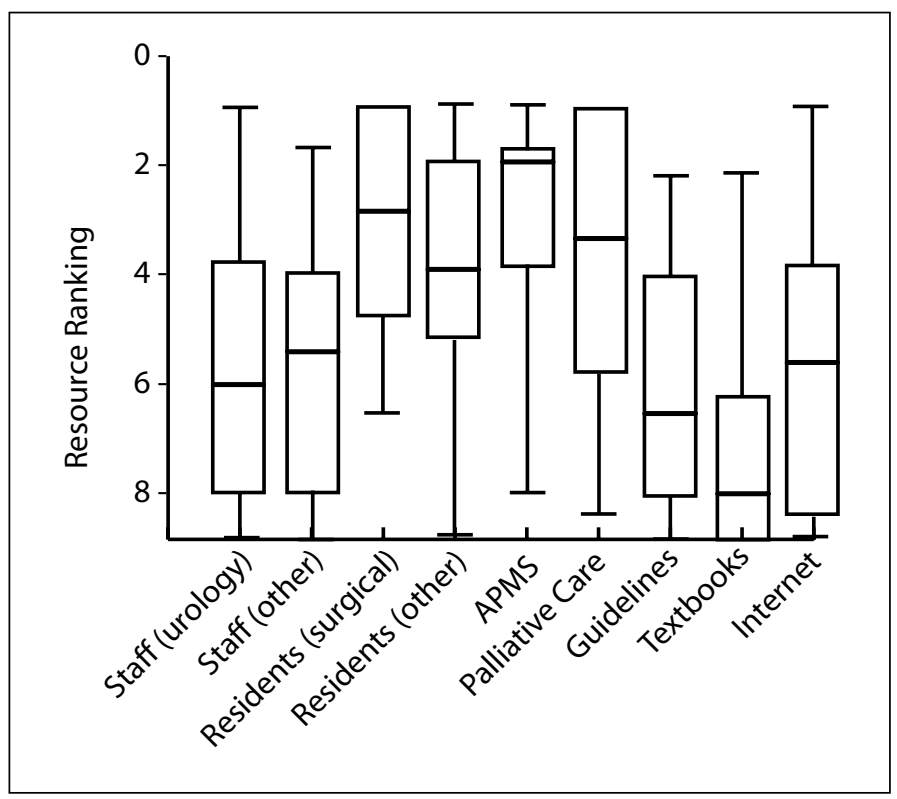

Fig. 2. Educational resources in pain management. Box and whisker plot (mean, $95 \%$ confidence limit) of ranking scores (1-9).

When asked specifically about the use of opioids in chronic pain, $61 \%(3.39 \pm 1.17)$ agreed that opioids are the first-line approach to treat moderately severe chronic pain in patients with cancer, and most $(>81 \%)$ correctly identified that regularly scheduled opioid dosing is more effective than "as needed" approaches and that opioids are less effective for neuropathic pain. Questions exploring specific knowledge of opioid use revealed significant self-identified gaps; only $32 \%$ agreed that they could safely convert a patient from parenteral opioids to oral opioids without references, and only 3 responded that they could confidently convert one opioid to another in an equi-analgesic dose (Table 1). This is further demonstrated in the results of a separate knowledge question where only $65 \%$ of respondents were able to accurately state the components of a Percocet (Endo Pharmaceuticals, Newark, DE) tablet. Similarly, the ability of the residents to convert parenteral morphine to its oral equi-analgesic dose was less than optimal at only $52 \%$ accuracy. Equi-analgesic dose conversion for other opioids, such as parenteral hydromorphone $(48 \%)$, oral codeine $(42 \%)$ and oral hydromorphone $(6 \%)$, also reflected this knowledge gap.

\section{Discussion}

Pain management is a common and complex issue for the urologist. Unrelieved pain is a major medical problem. ${ }^{7}$ At the end of the 1990s, the physiological and psychological consequences of acute and chronic pain were well-recognized. ${ }^{8}$ This became the impetus for a massive educational and clinical care campaign advocating for improved processes and outcomes rather than passive acceptance and dis- 


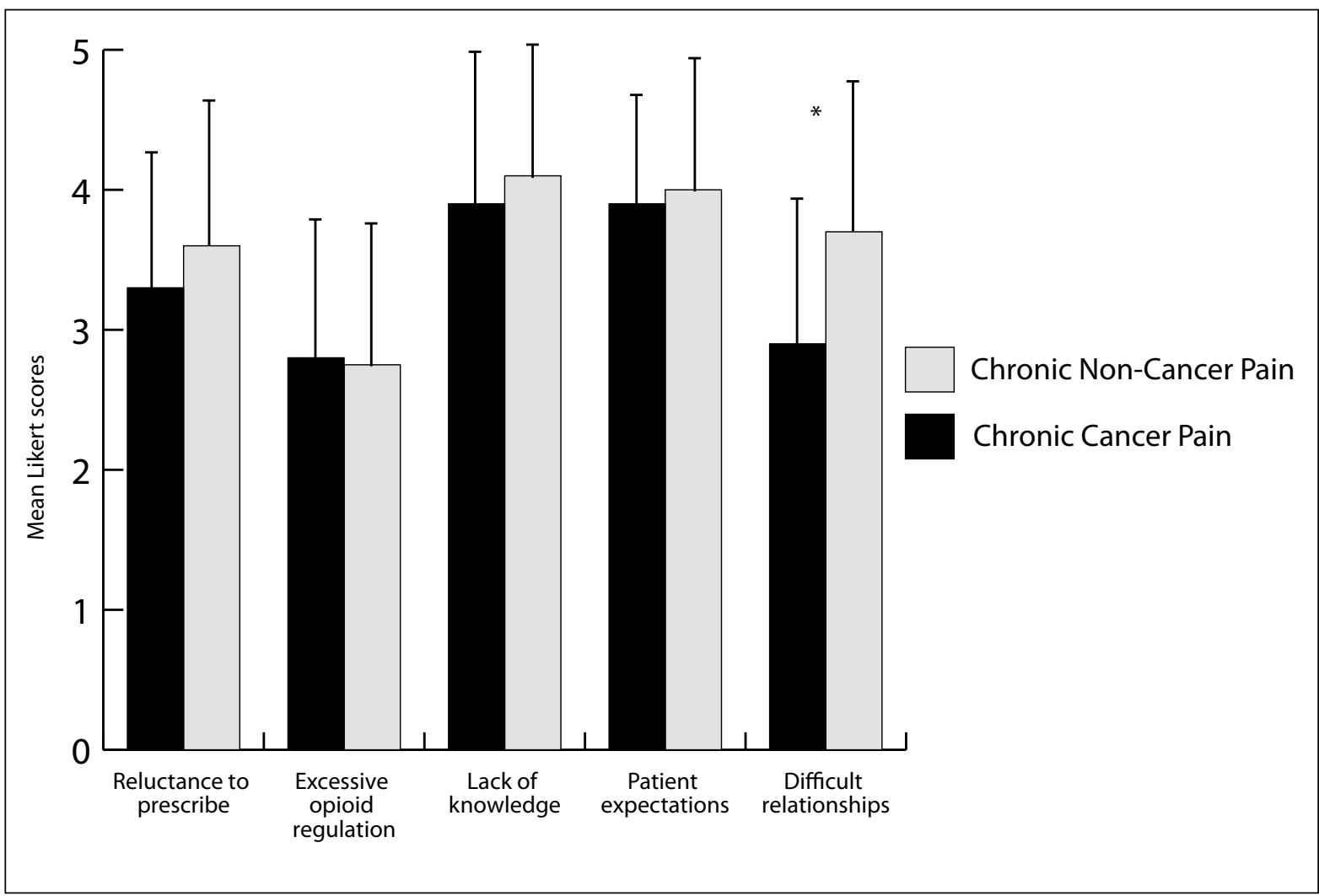

Fig. 3. Potential barriers to optimal chronic pain management in urological practice. Mean + standard deviation of Likert scores for cancer related (hashed) and non-cancer related pain issues. Perceived differences between groups were identified for potential difficulties in patient/physician relationships ( $p<0.001$, ANOVA, Bonferroni's correction).

missal of its consequences. Yet well into the second decade of the recognition of this clinical challenge, many barriers still exist in attaining the provision of optimal care, including deficiencies in physician education..$^{9,10}$

The results of this survey would suggest that formal teaching in pain management represents a disproportionately small percentage of the curriculum in urological postgraduate education. Despite the prevalence of pain, particularly in a surgical subspecialty, less than a quarter of urology residents across Canada received formal training in any pain management in their residency program. The residents feel that acute and chronic pain management should be important objectives in their training and would value a formal curriculum. This self-reported assessment of their programs, however, suggests that these principles of acute pain management are primarily learned experientially from their senior residents or fellows. Furthermore, knowledge and experience gained in chronic pain management was even less structured.

It is notable that even given the minimal formal teaching in acute pain management, most residents felt competent independently managing acute pain issues. This may be generally accurate; yet when we probed their actual knowledge, we found that their self-assessed familiarity and confidence in using a variety of analgesic agents was arguably poor. This translated into a similar knowledge gap when asked about specific tasks. The involvement of acute pain services in the contemporary academic centre may be a double-edged sword; surgical residents can observe their patients' management by this consulting service and learn from it, although at the same time their actual experience is diminished. This could have contributed to the confidence with which most residents felt they could successfully manage their patients' acute pain issues independently. When these same issues were raised regarding chronic pain, the residents not only had minimal confidence in their abilities, but they raised a number of barriers to providing care for their chronic pain patients. These barriers included a lack of a formal curriculum and role models, as well as a perceived difficulty relating to their patients. Although there is no direct evidence demonstrating suboptimal care for our patients, we must be cognizant of this potential given all of these challenges. ${ }^{11}$

The contrast in the residents' comfort level to manage chronic pain issues was apparent in this survey; only a minority $(19 \%)$ felt their training was adequate. Strengthening the pain management component in the program's academic curriculum could not only address not only the graduating residents' comfort level in this area, but could also provide 
Pace et al.

\begin{tabular}{|c|c|c|c|c|}
\hline Medication & $\begin{array}{l}\text { No understanding/ } \\
\text { no desire to learn }\end{array}$ & $\begin{array}{l}\text { No understanding but } \\
\text { desire to learn }\end{array}$ & $\begin{array}{l}\text { Some understanding } \\
\text { (enough to prescribe) }\end{array}$ & $\begin{array}{l}\text { Understand/could } \\
\text { explain to others }\end{array}$ \\
\hline Morphine & $0(0 \%)$ & $1(3 \%)$ & $21(72 \%)$ & $7(24 \%)$ \\
\hline Codeine & $2(7 \%)$ & $1(3 \%)$ & $20(69 \%)$ & $6(21 \%)$ \\
\hline Fentanyl & $2(7 \%)$ & $16(55 \%)$ & $11(38 \%)$ & $0(0 \%)$ \\
\hline Hydromorphone & $1(3 \%)$ & $1(3 \%)$ & $19(66 \%)$ & $8(28 \%)$ \\
\hline Oxycodone & $0(0 \%)$ & $6(21 \%)$ & $20(69 \%)$ & $3(10 \%)$ \\
\hline $\begin{array}{l}\text { Slow release opioid } \\
\text { preparations }\end{array}$ & $1(3 \%)$ & $13(45 \%)$ & $14(48 \%)$ & $1(3 \%)$ \\
\hline Tramadol & $3(10 \%)$ & $14(48 \%)$ & $9(31 \%)$ & $3(10 \%)$ \\
\hline $\begin{array}{l}\text { Acetaminophen/ } \\
\text { oxycodone }\end{array}$ & $1(3 \%)$ & $9(31 \%)$ & $12(41 \%)$ & $7(24 \%)$ \\
\hline $\begin{array}{l}\text { Acetaminophen/ } \\
\text { codeine }\end{array}$ & $1(3 \%)$ & $2(7 \%)$ & $17(59 \%)$ & $9(31 \%)$ \\
\hline Pregabalin & $3(10 \%)$ & 17 (59\%) & $9(31 \%)$ & $0(0 \%)$ \\
\hline Gabapentin & $2(7 \%)$ & $19(66 \%)$ & $8(28 \%)$ & $0(\%)$ \\
\hline Amitriptyline & $2(7 \%)$ & $18(62 \%)$ & $8(28 \%)$ & $1(3 \%)$ \\
\hline
\end{tabular}

positive role models and emphasize the strong relevance to many aspects of patient care. ${ }^{12}$ Currently, there are very few resources dedicated to developing skills in pain management for urology residents. In fact, even most urology textbooks devote little attention to these important concepts. ${ }^{13}$ Similarly there are no specific guidelines on pain management issues in urology and few urologists are familiar with the available general pain guidelines or recommendations. ${ }^{14,15}$

Pain management should become a recognized, properly resourced component of the academic curriculum for our residents. Raising the profile of pain management above the current experientially-based, peer-taught approach should help ensure our future consultants attain the confidence and competence to manage these often complex clinical problems without completely relying on anesthesia-based pain services. ${ }^{16}$ The Accreditation Council for Graduate Medical Education (ACGME) program requirements for Graduate Medical Education in Urology does not mandate any specific curriculum dedicated to pain management. ${ }^{17}$ The objectives for acute postoperative pain management are outlined in the Royal College Objectives of Surgical Foundations Training; coherent curriculum mapping to these objectives would improve the residents' understanding. ${ }^{18}$ If a similar set of objectives in these national organizations in urology were developed regarding chronic pain management, we could encourage both supervisors and consultants to give the proper teaching, experience and role models required to address this neglected area.

The present study was conducted as a convenience sample with the participation of only PGY-5 urology residents in Canada, and may not represent other specialties in other jurisdictions. However, the literature suggests otherwise; similar knowledge gaps have been identified in other specialties in multiple countries. ${ }^{19-22}$ Moreover, this may not be a fully representative sample of postgraduate trainees although these residents were specifically chosen close to completion of their training to ensure that they had experienced all rotations and educational curricula set out by their respective programs. This survey represents only a snapshot of their self-reported attitudes towards and experience of pain management within their training. On the other hand, the response rate of the residents and the consistency of responses throughout the survey could attest to the veracity of the results and our interpretation. With respect to the potential knowledge gap identified in the survey, this could have been influenced by the fact that this convenience sample was drawn during an examination preparation course, and this may have distracted the participants and therefore affected the responses given. That being said, it is commonly believed that residents within months of their certification exams are at the height of their theoretical knowledge acquisition. ${ }^{23}$

\section{Conclusion}

The results from the present study underscore the variable experience, attitudes and actual knowledge of pain management in a urology residency. The issues demonstrated around the poor uptake of formal teaching and knowledge of acute and chronic pain is likely not unique to urology. This survey revealed a considerable disconnect in instruction/ evaluation of pain management skills, as most residents recognized its importance but also conceded that only modest formal teaching was taking place and that their skills were limited, particularly in the management of chronic pain.

Competing interests: Dr. Pace, Dr. Jaeger and Dr. Nickel declare no competing financial or personal interests. Dr. Siemens is the Editor-in-chief at CUAJ. 
This paper has been peer-reviewed.

\section{References}

1. Nickel JC, Nigro M, Hosking D, et al. Diagnosis and treatment of prostatitis in Canada. Urology 1998;52:797-802. http://dx.doi.org/10.1016/S0090-4295(98)00297-0

2. Nickel JC, Teichman JMH, Downey J, et al. Prevalence, diagnosis, characterization, and treatment of prostatitis, interstitial cystitis, and epidymitis in outpatient urological practice: The Canadian PIE study. Urology 2005;66:935-40. http://dx.doi.org/10.1016/j.urology.2005.05.007

3. Levy MH. Pharmacologic treatment of cancer pain. N Engl J Med 1996;335:1124-32. http://dx.doi. org/10.1056/NEJM199610103351507

4. Brever B, Fleishman SB, Portenoy RK, et al. Medical oncologists' attitudes and practice in cancer pain management: A national survey. J Clin Oncol 2011;36:4769-75. http://dx.doi.org/10.1200/ JC0.2011.35.0561

5. Gallagher R, Hawley $P$, Yeomans W. A survey of cancer pain management knowledge and attitudes of British Columbian physicians. Pain research \& management 2004;9:188.

6. Leveridge $M$, Beiko $D$, Siemens $R$, et al. Health advocacy training in urology: a Canadian survey on attitudes and experience in residency. Can Urol Assoc J 2007;1:363-9.

7. Kuehn BM. Opioid prescriptions soar increase in legitimate use as well as abuse. JAMA 2007;297:249251.

8. Phillips DM. JCAHO pain management standards are unveiled. JAMA 2000;284:428-9. http://dx.doi. org/10.1001/jama.284.4.428

9. Cohen MZ, Easley MK, Westbrooks JB, et al. Cancer pain management and the JCAHO's pain standards: an Institutional Challenge. J Pain Symptom Manage 2007;25:519-27. http://dx.doi.org/10.1016/ S0885-3924(03)00068-X

10. Apfelbaum JL, Chen C, Tong JG, et al. Postoperative pain experience: Results from a National survey suggest postoperative pain continues to be undermanaged. Anesth Analg 2003;97:534-40. http:// dx.doi.org/10.1213/01.ANE.0000068822.10113.9E

11. Green CR, Wheeler JR, Guerrero E, et al. Analysis of the physician variable in pain management. Pain Med 2001;2:317-27. http://dx.doi.org/10.1046/i.1526-4637.2001.01045.x
12. Weissman DE, Griffie J, Dahl JL. A role model program to promote institutional changes for management of acute and cancer pain. J Pain Symptom Manage 1997;14:274-9. http://dx.doi.org/10.1016/ S0885-3924(97)00224-8

13. Campbell-Walsh Urology (10th edition). Philadelphia: Saunders;2011:2035.

14. CUA Guidelines; 2013. http://www.cua.org/guidelines_e.asp. Accessed November 26, 2013.

15. AUA Guidelines; 2013. https://www.auanet.org/education/aua-guidelines.ffm. Accessed November 26, 2013.

16. Miaskowskia C, Crews J, Ginsberge B, et al. Anesthesia-based pain services improve the quality of postoperative pain management. Pain 1999:80:23-9. http://dx.doi.org/10.1016/S0304-3959(98)00192-4

17. ACGME program requirements for graduate education in urology; 2012. hittps://www.acgme.org/acgmeweb/Portals/0/PFAssets/ProgramRequirements/480_urology_07012013.pdf. Accessed November 14, 2013.

18. Objectives of surgical foundations training; 2011. Version 1.1. http://www.royalcollege.ca/cs/groups/ public/documents/document/y2vk/mday/ edisp/tztest3rpsced002644.pdf. Accessed November 26, 2013.

19. Ger LP, Ho ST, Wang JJ. Physicians' knowledge and attitudes toward the use of analgesics for cancer pain management: a survey of two medical centers in Taiwan. J Pain Symptom Manage 2000;20:335-44. http://dx.doi.org/10.1016/S0885-3924(00)00207-4

20. Wilsey BL, Fishman SM, Bertakis KD, et al. Chronic pain management in the emergency department: a survey of attitudes and beliefs. Pain Med 2008;9:1073-80. http://dx.doi.org/10.1111/j.15264637.2007.00400.x

21. Morley-Forster PK, Clark AJ, Moulin DE, et al. Attitudes toward opioid use for chronic pain: a Canadian physician survey. Pain Res Manag 2003;8:189-94.

22. Scanlon MN, Chugh U. Exploring physicians' comfort level with opioids for chronic noncancer pain. Pain Res Manag 2004;9:195-201.

23. McDonald FS, Zeger SL, Kolars JC. Factors Associated with Medical Knowledge Acquisition during Internal Medicine Residency. J Gen Int Med 2007;22:962-8. http://dx.doi.org/10.1007/s1 1606-007-0206-4

Correspondence: Dr. Melanie Jaeger, Department of Anesthesiology and Perioperative Medicine, Victory 2, Kingston General Hospital, 76 Stuart St., Kingston, ON K7L 2V7; fax: 613-548-1375; jaegerm@kgh.kari.net 